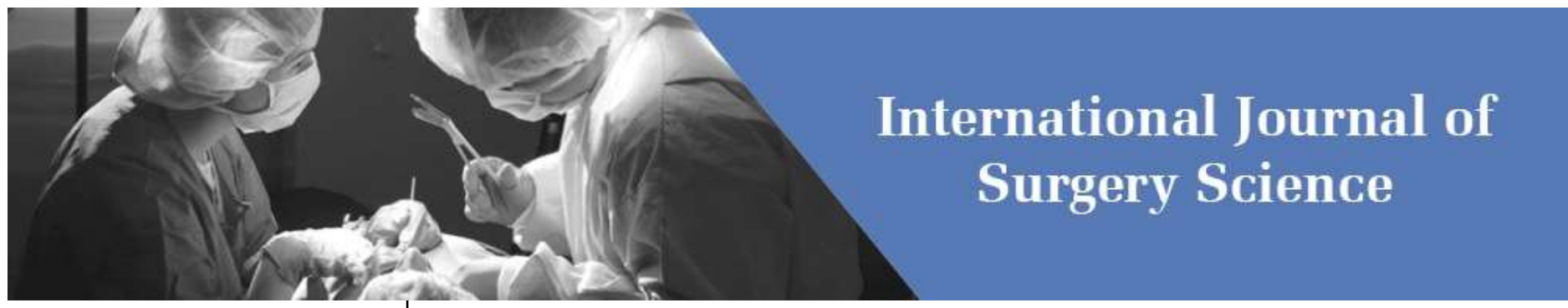

E-ISSN: 2616-3470

P-ISSN: 2616-3462

(C) Surgery Science www.surgeryscience.com

2021; 5(2): 261-265

Received: 15-02-2021

Accepted: 17-03-2021

Dr. Yogiraj Nainpuriya

M.S. General Surgery

Associate Professor General

Surgery J.M.C. Jhalawar,

Rajasthan, India

Dr. Biram Chand Mewara

M.S. General Surgery, Associate

Professor General Surgery J.M.C.

Jhalawar, Rajasthan, India
Corresponding Author:

Dr. Biram Chand Mewara

M.S. General Surgery, Associate

Professor General Surgery J.M.C.

Jhalawar, Rajasthan, India

\section{Trends in keloids an hypertrophic scars}

\author{
Dr. Yogiraj Nainpuriya and Dr. Biram Chand Mewara
}

DOI: https://doi.org/10.33545/surgery.2021.v5.i2e.704

\section{Abstract}

The word "KELOID" has been taken from Greek language (Cheloide) meaning thereby "like crab's claw".Alibert 1806 and modified by himself in 1817 An abnormal proliferation of fibroblast collagen fibrils and immature blood vessels usually on a pre-existing scar in dermis surrounded by normal tissues. A spontaneous keloid has no history of injury or operation and as such there is no scar.

Hypertrophic scar is one in which there is proliferation of fibrous tissue within the limits of scar and this growth becomes inactive in due course of time.

Several methods of treatment have been described but complete eradication has not achieved so far.

We are studying on different modalities of treatment and outcomes.

Keywords: Keloid, crab's claw, Hypertrophic scar, immature blood vessels

\section{Introduction \\ Aims and Objects}

\section{Material and Methods}

This study comprises a clinical study of 120 cases of Keloids and hypertrophic scars, who came as indoor or outdoor patients in various departments of S.R.G. Hospital Jhalawar during 2016 to 2020. Detailed history was recovered and thorough clinical examination was done as follow:-

I. Interrogation of Patient Name; Case No.; Age; Sex; Religion; Address; Registration, No, DOA, DOD, Provisional diagnosis, Complaints with duration, Growth; Itching; Pain; cause; disfigurement; H/O present illness; H/O past illness, - Family History.

\section{General Examination: Vitals, general conditions.}

III. Local examination-as: Number of lesion, site, size, shape, colour of lesion, colour of patient's skin, surface, consistency, tenderness, mobility, spreading under the skin / involving normal skin.

IV. Investigation: blood $\mathrm{Hb}, \ldots$ Blood grouping... FNAC of lesion, Histopathological examination.

\section{Treatment}

1. Local injections: Intralesional injection of triamcinolone acetonide (Kenacort) 10mg or $40 \mathrm{mg}$ or according to size of lesion was given through a 24 gauge needle $\sigma \psi$ ringe. The injection was given along the margins of lesion to start with one end then in-side the lesion which was repeated after an interval of 2 to 3 weeks. We did not use local block anaesthesia.

2. Surgery: under G.A., after cleaning and painting with savlon and sprit, the incision was given along the margins of lesion. The lesion was excised by leaving some part of it at the junction of it with normal skin (intra keloidal). A kenacort injection was given along the cut edges. Under complete haemostasis, subcutaneous stitches were applied with 4 zero chromic catgut and skin stitches with 5 zero monofilament nylon. A pressure bandage was applied after dressing or aluminium clip pressure leaved on dressing. In some cases we used split skin grafting to cover the raw area. The S.S.G was taken from the thigh and a pressure bandage was applied over donor site. Pre and post-operative period kenacort injection also given in operating scar. 
3. Local Kenalog joint: We advise local application of Kenalog joint, in those cases in which we want only symptomatic relief.

\section{Follow Up}

As patient attained hospital up to 1 year.

\section{Observation}

The following observations are based on clinical examination, investigation, treatment and follow up of 120 patients of Keloids and Hypertrophic scars. These cases attended various department of S.R.G. hospital Jhalawar (Rajasthan), as indoor and outdoor patients. Out of 120 patients 88 were of Keloids and 32 of Hypertrophic scars.

1. No of Lesion In120 patients: Most of the patients i.e. $60 \%$ had single lesion. The total number of lesions were single in 98 patients and multiple lesions were present in 22 patients.

2. According to this Observation shows that the ratio between male and female patients was 1:1.3 (Male 43.3\%, Female $56.6 \%)$. The multiple lesions were also common in weaker sex.

3. Total number of keloidal patients $=88(73.3 \%)$ and the common age group for Keloids was 22 to 30 years, none of the patient was below the age of 8 or above 70 years. Total number of Hypertrophic scar patients $=16(26.6 \%)$. The Hypertrophic scars were common in patients of 11 to 30 years of age. Multiple lesions were also present in same age of group.

4. According to religion: Out of 120 patients, 114 were Hindus and 6 were Muslims.

5. This study also shows that most of the keloid patients i.e. $72.5 \%$ gave history of growth lesion less than 2 years, 3 patients were having lesions for 20 years but they did not attend the hospital because pain and itching were absent during this period. The Hypertrophic scar patients rarely attended the hospital after 2 years of lesion. This may be due to that pain and itching may subside after 2 years and spontaneous regression may take place.

6. A combination of above symptoms like pain itching and disfigurement were present in most of the cases. Only disfigurement and growth was complained by 3 patients. Infection or ulceration was rare in Keloid patients but may present in Hypertrophic scars (marzolin ulcer).

7. In this study the commonest cause of Keloids and Hypertrophic scars was burn. Other common causes of Keloids were operations, lacerated wounds, injection, vaccination, ear piercing, trauma and skin graft (donor area). In one case, the Keloids over thigh occurred after split skin grafting but other lesions were spontaneous in origin. Recurrence of Keloid after surgery was found in 24 patients (20\%). They were operated for Keloid-once, twice or thrice. Recurrence rate was negligible in hypertrophic scars

8. Only two patients (3.3\%) gave positive family history of Keloids. In case no.35 patient's mother had multiple keloid lesions on different parts of body. In case no.40, patient's mother and younger brother had Keloids.

9. According to this the commonest sites for Keloids were presternal and deltoid region. Other common sites were abdomen, breast, thigh, leg, forearm, ear lobule, face and chest. Eleven patients had multiple lesions on different parts of body except palm, sole and external genitalia. Generally the contracture was associated with these multiple lesions. The commonest cause of lesions over pre-sternal area was infection (Boils), on ear lobule was ear prick, on abdomen was operation and on deltoid region was vaccination.

10. The lesions ranged in size from $1 / 2$ inch $\times 1 / 2$ inch to 12 inches $x 1 / 2$ inch. Most of the lesions $(65 \%)$ were between $1 / 2$ to 4 inch $x \frac{1}{2}$ to 3 inches.

11. Shape was variable in each case but butterfly shape was present over pre-sternal area and coin or oval shape over deltoid region, postoperative lesions were generally elliptical or linear and post burn lesions were irregular in shape.

12. The colour of the lesion at the time of examination was pink or red or pale. Most of the lesions (56.6\%) were pink. Majority of patients i.e. $73.33 \%$ had brown coloured skin.

13. Most of the Keloid lesions were firm and hypertrophic scars were soft to firm in consistency. Consistency varied according to the duration of growth. If the lesion was of short duration, it was soft and if duration was long, the consistency was firm. Only one patient had a hard lesion, which was operated upon Keloid twice.

\section{Treatment and Results}

Table 1: Various mode of treatment

\begin{tabular}{|c|c|c|c|c|c|c|}
\hline \multirow{2}{*}{ Mode of treatment } & \multicolumn{2}{|c|}{ Keloids } & \multicolumn{2}{c|}{ Hypertrophic scars } & \multicolumn{2}{c|}{ Total } \\
\cline { 2 - 7 } & No. of lesions & \% & No. of lesions & \% & No. of lesions & \% \\
\hline Surgery & 16 & 13.33 & 6 & 5.0 & 11 & 18.33 \\
\hline Local injections of corticosteroids & 56 & 46.66 & 10 & 8.3 & 33 & 55.0 \\
\hline Kenalog ointment locally & 16 & 13.33 & 16 & 13.33 & 16 & 26.66 \\
\hline Total & 88 & 73,33 & 32 & 26.66 & 60 & 100.0 \\
\hline
\end{tabular}

Most of the lesions (55\% or 33 cases) were treated only intralesion triamcinolone acetonide (Kenacort) $10 \mathrm{mg}$ or $40 \mathrm{mg} / \mathrm{c} . c$. A combined treatment in the form of surgery and postoperative pressure or pre and postoperative local kenacort injections was given. When patient had mild itching or pain at the site of lesion without disfigurement, we advised local application of Kenalog or betnovate ointment. This corticosteroid local application helpful to relieve pain and itching to some extent.

Table 2: Outcome of various types of treatment

\begin{tabular}{|c|c|c|c|c|c|c|c|c|c|c|c|c|}
\hline \multirow{4}{*}{$\begin{array}{l}\text { Mode of surgical } \\
\text { treatment }\end{array}$} & \multirow{4}{*}{ No. of pts. } & \multirow{4}{*}{$\%$} & \multicolumn{6}{|c|}{ Response to treatment } & \multicolumn{4}{|c|}{ Result } \\
\hline & & & \multirow{2}{*}{\multicolumn{3}{|c|}{$\begin{array}{c}\text { Subjective } \\
\text { Pain and itching }\end{array}$}} & \multirow{2}{*}{\multicolumn{3}{|c|}{$\begin{array}{c}\text { Objective } \\
\text { Growth } \\
\end{array}$}} & \multicolumn{2}{|c|}{ Cure } & \multicolumn{2}{|c|}{ Recurrence of $\sigma \psi$ mptoms } \\
\hline & & & & & & & & & \multirow{2}{*}{ No of pts. } & \multirow{2}{*}{$\%$} & \multirow{2}{*}{ No of pts. } & \multirow{2}{*}{$\%$} \\
\hline & & & +- & + & ++ & +- & + & ++ & & & & \\
\hline Surgery \& pressure & 8 & 6.6 & 0 & 1 & 3 & 0 & 0 & 4 & 6 & 75.0 & 2 & 25.0 \\
\hline Surgery \& Kenacort & 8 & 6.6 & 0 & 0 & 4 & 0 & 0 & 4 & 8 & 100.0 & 0 & 0 \\
\hline
\end{tabular}




\begin{tabular}{|c|c|c|c|c|c|c|c|c|c|c|c|}
\hline injection \& Pressure & & & & & & & & & & & \\
\hline Total & 16 & 13.3 & 0 & 1 & 7 & 0 & 0 & 8 & 14 & 87.0 & 2 \\
\hline
\end{tabular}

$+-=$ no improvement

$+=$ to moderate relief $\& 25$ to $50 \%$ regression of growth.

$++=$ complete disappearance of symptoms and more than $50 \%$ regression.

Total number of patients $=60$

Total number of patients treated by surgery $=8(13.3 \%)$

Out of 8 patients, excision and repair was done in 4 patients (50

$\%)$ and excision and split skin grafting was done in 4 patients $(50 \%)$.

Postoperative pressure was applied in 4 patients to prevent recurrence and was kept for 3-6 months. In 2 patients, kenacort injections were given preoperatively and during operation, into the wound at the time of primary suturing.

\section{Corticosteroid Injection and Results}

Table 3: Results of injection of corticosteroids

\begin{tabular}{|c|c|c|c|c|c|c|c|c|c|c|c|c|c|}
\hline \multirow{4}{*}{$\begin{array}{l}\text { Type of } \\
\text { injection }\end{array}$} & \multirow{4}{*}{$\begin{array}{l}\text { No. of } \\
\text { pts. }\end{array}$} & \multirow{4}{*}{$\%$} & \multicolumn{6}{|c|}{ Response to treatment } & \multicolumn{4}{|c|}{ Result } & \multirow{4}{*}{$\begin{array}{l}\text { Loss of } \\
\text { following }\end{array}$} \\
\hline & & & \multirow{2}{*}{\multicolumn{3}{|c|}{$\begin{array}{c}\text { Subjective } \\
\text { Pain and itching } \\
\end{array}$}} & \multirow{2}{*}{\multicolumn{3}{|c|}{$\begin{array}{c}\text { Objective } \\
\text { Growth } \\
\end{array}$}} & \multicolumn{2}{|c|}{ cure } & \multicolumn{2}{|c|}{ Recurrence of symptoms } & \\
\hline & & & & & & & & & \multirow{2}{*}{$\begin{array}{c}\text { No of } \\
\text { pts. }\end{array}$} & \multirow{2}{*}{$\%$} & \multirow{2}{*}{ No of pts. } & \multirow{2}{*}{$\%$} & \\
\hline & & & +- & + & ++ & +- & + & ++ & & & & & \\
\hline Kenacort & 25 & 41.66 & 0 & 16 & 8 & 1 & 20 & 4 & 22 & 95.6 & 1 & 4.3 & 2 \\
\hline Wycort & 3 & 5.0 & 0 & 2 & 1 & 2 & 1 & 0 & 1 & 33.3 & 2 & 66.6 & 0 \\
\hline Total & 28 & 46.66 & - & - & - & - & - & - & 23 & 88.4 & 3 & 11.3 & 2 \\
\hline
\end{tabular}

pts. = patients

$+-=$ no improvement

$+=$ to moderate relief \& 25 to $50 \%$ regression of growth.

$++=$ complete disappearance of symptoms and more than $50 \%$ regression.

Total number of patients $=60$

Total number of patients treated by corticosteroids $=28$

According to table no. 3 the kenacort injection was given in 25 lesions and Wycort injection was given in 3 lesions. Out of 25 lesions, 22 were Keloids and 3 were of Hypertrophic scars. The dose of Kenacort was variable according to size of lesion (average dose10 to $20 \mathrm{mg}$.) And interval between two injections was 2-3 weeks. The dose and number of injections depends on size and duration of lesion. Better results were obtained by Kenacort injections than other preparations of corticosteroid. The above table also shows that some beneficial effect was noted in all cases. $33.3 \%$ of lesions which were treated by intralesional Kenacort, flattened out completely and another $50 \%$ became much softer. Softening was first noted at 2-3 weeks after the first injection and progressed with each subsequent injection.

Table 4: Number of Dose Given To Patients

\begin{tabular}{|c|c|c|}
\hline No. of injections & No. of patients & \% \\
\hline 1 does & 5 & 20 \\
\hline 2 doses & 9 & 36 \\
\hline 3 doses & 16 & 72 \\
\hline 4 doses & 6 & 24 \\
\hline More than 4 doses & 4 & 16 \\
\hline
\end{tabular}

No. of patients 25

Range of doses $=$ According to size of lesion normally 10 to $40 \mathrm{mg}$.

Intervals between injections 2 to 3 weeks.

Table no. 5 shows that most of the patients $(72 \%)$ were given 2 to 3 doses at an interval of 2 to 3 weeks. 5 patients were given a single dose 2 of them did not came during follow up and another 3 had symptomatic relief and softening of lesion. Two patients had been given more than 4 injections at an interval 2 to 3 weeks till the growth regresses.

\section{Discussion}

In this study 44 patients $(73.33 \%)$ of Keloids and $16(26.66 \%)$ patients of hypertrophic scars were treated by various methods of treatment and followed up from 3 months to 1 year.

\section{Sex}

In this series 26 patients $(43.33 \%)$ were males and $34(56.66 \%)$ were females. The male to female ratio was 1:1.3 this has also been observed by other workers. The high incidence in females has been attributed to the relationship of keloid to female hormones (rayer 1935).

Griffith (1966) [27] reported that keloids were common in females $(58 \%)$ than males $(42 \%)$, vallis (1967) found that most of the patiest $(75 \%)$ were females.

\section{Age}

In the present study $75 \%$ of the patients were between 11 to 30 years of age. Average age of patients was 26.06 years. The overall range was 8 years to 70 years. These findings are very much similar to findings of other wprkers. This indicates the hormonal factor as a main aetiological factor of keloids. Because hormonal stimulation is found high in second decade (grab and stone 1942).

Cosmen, et al. (1961) ${ }^{[7]}$ reported the average age incidence to be 20.8 years. Griffith (1966) ${ }^{[27]}$ reported the average age to be 20 years Where as vallis (1967) noted the average age of occurrence to be 20 years.

\section{Duration of Lesion Prior To Treatment}

In this study $65.9 \%$ (29) patients of keloids and 100\% (16) patients of hypertrophic scars had the lesions for 2 years or less than 2 years. $6.8 \%$ (3) patients of keloids had the lesions over 20 years but the symptoms and signs developed only during last 6 months to 2 years. None of the case of hypertrophic scars had complain beyond 2 years of duration. The average duration for keloids was 2 years 3 months and for hypertrophic scar was 9 months.Present observations are similar to be finding of Cosman et al. (1961) ${ }^{[7]}$ who reported the average duration to be 4.9 years and Griffith (1966) ${ }^{[27]}$ has reported the duration of lesions from 6 months to 12 years. 


\section{Symptoms}

In this series $95 \%$ (110) of patients were having combination of symptoms like pain, itching with or without complaint in 5\% (6) of cases, 8 (6,6\% lesions were infected or ulcerated. These observations are nearly the same as of other workers.

Griffith (1966) ${ }^{[27]}$ found that $76.8 \%$ patient had pain \&itcing with or without disfigurement but $12.8 \%$ patient complaind disfigurement as major symptom.

\section{Family History}

In this series only 4 patients $(3.3 \%)$ gave history of keloids in their mothers. One of them also gave the history of keloids in his younger brother. This has been noted by other workers.Heredity was blamed by rayer(1935) as a aetiological factor in the development of keloids

\section{Aetiological Factors}

In the present study $18.3 \%$ (11) of keloids followed burns \& $16.6 \%$ (10 cases) followed surgical operations. Infection and vaccination were the initiating factor in 11.6 (7) of lesions respectively. Lacerated wounds and trauma were causative factors in 15\% (9) of lesions. Other causes were ear piercing, skin graft (donor area) and rarely insect bite. The main cause of keloids over ear lobule was ear piercing and over abdomen was surgery.

Cosman et al. (1961) ${ }^{[7]}$ noted thainitiation factors in decreasing factor as accidental trauma, surgical procedures, infection, burns etc.

\section{SITE}

In this study the commonest site for keloid was presternal area ( $20 \%$ or 12 lesions) and next common was deltoid region $(15 \%$ or 9 lesions). The other common sites were abdomen, breasts, thigh, ear lobule, neck, arm, forearm atc. In decreasing order. No case of keloid was recorded over palm, sole or external genitalia. This is similar to observations of other workers. Cosman (1961) ${ }^{[7]}$ noted the common sites of lesions, in order of preference as ear, face, neck, abdomen, scalp and shoulder. In 1966, Griffith observed the common sites in order of sequence as presternal area, breast, arm, back, earlobule, abdomen, shoulder etc.

\section{Colour Of Lesion and Consistency}

In this study $56.6 \%$ (34) of lesions were pink in colour and firm in consistency. $21.6 \%$ lesions were red. Colour and consistency depend upon their pigment content, vascularity and duration of lesion.

\section{Colour Of Patients Skin}

In the present study $73.33 \%$ (88) patients were brown skinned, $20 \%$ (24) dark skinned and $6.6 \%$ (8) were fair skinneds. This is due to increased concentration of melanocyte pigment in brown and dark skinned patients. Mastas (1896) estimated the ratio of keloid in coloured to white patients as 9:1 and Fax (1909) ${ }^{[12]}$ as 19:1.

\section{Treatment}

The mode of treatment in all the cases was divided into four categories. One was surgery (18.3\% of 11 patients) which included Surgery and pressure Surgery and corticosteroid injection locally.

The second category included 55\% (66) of patients treated by local injection of corticosteroid.

In which included $32(26.6 \%)$ cases were dealt by corticosteroid ointment locally.

Overall recurrence rate of surgically treated patients was $25 \%$ (1 out of 8). Better results were obtained when corticosteroid injections were used along with surgery \& postoperative pressure was applied over the site of lesion for 3 to 6 months. Neson, L.H. (1942) tresated 51 lesion in 49 patients. The treatment was divided in four groups as follows:- (a) excision and approximation, (b) excision and radiation, (c) radiation alone and (d) pressure alone. Most satisfactory results were obtained when patients were treated by excision and radiotherapy.

Conway, et al. (1960) ${ }^{[6]}$ treated cases by intramarginalexcision and closure or skin grafting. Themethodes used by him were (a) excision alone (b) excision and local injections of cortison derivatives (c) excision and X-ray therapy, (d) excision and injections of crtison derivatives locally and X-ray therapy.Better results were obtained giving cortison derivatives locally and $\mathrm{x}$ ray therapy.

By surgery our cure rate was $100 \%$ when treatment was accompanied by intralesional injections of triamcinolone acetonide and post operative pressure, results of other authers is also nearly the same with a variation of $10 \%$ or so. Which is insignificant.

\section{Local Treatment Acetonide (Kenacort) Injection}

In the present series $46 \%$ (28) of lesions were treated by local injections of corticosteroids either kenacort ( $41 \%$ or 25 lesions) or Wycort (5\% or 3 lesions). Patients receiving kenacort injections showed a cure rate of $95.6 \%$ (lesions with recurrencerateofsymptomes $4.3 \%$ (1lesion) whereas those receiving Wycort injections had cure rate of $33.3 \%$ (1) and recurrence rate of symptoms $66.6 \%$ (2)

Griffith (1966) ${ }^{[10]}$ treated 37 patients of keloidal lesions by intraleasional injections of triamcinolone acctonide (kenacort) and noted complete dissolution in $51 \%$ (19) of lesion, partial dissolution (softening) in $40 \%$ (15) of lesion.symptoms eliminated $59 \%$ (20), Symptoms reduced $41 \%$ (14)

Ketchum et al. (1966) [27] Treated Hypertrophic scars and keloids by triamcinolone acetonide and noted a definite regression in $88 \%$ of the cases. Pruritis and paresthesia disappeared within 3 to 5 day following injection.

Griffith et al. (1970) [29] treated 61patient only by intralesionalkenacort injections of which $42(69 \%)$ flattened out completely another $13(21 \%)$ become softer. In 5 patient $(8 \%)$ there was no improment and one patient was lost during follow up.

Intralesional injections of triamcinolone acetonide 3-5 injections at an interval of $2-3$ weeks gave the cure rate of $83.3 \%$. All patients had symptomatic relief. This variation is insignificant in view of the variation in the selection of cases.

Surgery should be done only as a last resort if the lesion sare of big size, multiple and unsightly situations. Surgery should be followed by postoperative local injections of triamcinolone acetonide and maintenance of pressure by dressing or splints.

\section{Summary and Conclusions}

44 patients of keloids and 16 patients of hypertrophic scar were treated by

1. Surgery

2. Local injections of corticosteroids

3. Local application of corticosteroids ointments

Follow up was done from 3 months to 1 year. The results of treatment of these patients with recurrence rate have been analysed. The relevant literatures have been reviewed.

Most of the patients studied, had single lesion but more than one lesions were not uncommon. The lesions were more common in female than males.

The average age of patients was 26.05 years. Most of the patients were hindus except 2 (Mohammedans).

The average duration for keloids was 2 years 3 months and for 
hypertrophic scars was 9 months.

Most of the patients had pain, itching and disfigurement. Only 4 patients had infections and 3 patients did not complain about pain and itching but of disfigurement.

Only two patients gave history of keloids in their family relations eg. mother and brother.

The commonest cause of disease was burn. Other causes were operations, lacerated wounds, infections, vaccination, ear piercing, trauma, skin graft (donor area) and insect bite, in decreasing order.

Commonest site were presternal and deltoid regions. Other common sites were abdomen, breasts, thigh, legs, forearm, ear lobules, face, chest, neck, arms and hands (dorsum) in decreasing order.

Size and shape was variable and the common colour of the lesion was pink or red. Surface was smooth or nodular. The consistency was firm or soft except one (hard). Lesion was movable with skin movement. It was not adherent to deeper structures. Keloids were involving the normal skin or spreading under normal skin.

Intralesional injections of triamcinolone acetonide gives fairly good results and recurrence rate is lowest.

Surgery should be done only as a last resort, if the lesions are of big size, multiple and unsightly situations. Surgery should be followed by postoperative local injections of triamcinolone acetonide and maintenance of pressure dressing or splints.

\section{References}

1. Alhady Syed MA. Keloids in various races: A review of 175 cases. Sivanantharajah, k Plast.\&Reconstr Surq 1969;44:564.

2. Asboe-Hansen G. Treatment of Keloid with topical Brodthagen, H., and injections of hydrocortisone Zacharial, L. Acetate. Arch.Dermal \& Syph 1956;73:162.

3. Baker BL, Whilaker. Interference with wound healing W.L.: by local action of adrenocortical Steroids and endocnnology 1950;46:544-551.

4. Bohrod MG Keloids and sexual selection: a Study in the racial distribution of Disease. Arch. Dermat \& Syph 1937;36:19.

5. Bloom D. Heredity of Keloids. N.Y. state J. Med. 1956;56:511.

6. Conway H, Gillette RW. differential diagnosis of Keloids Smith, J.W., andand hypertrophic scars by tissue culture technicq Findlay, A. e with notes on therapy of keloids by surgical Excision and Decadrone. Plast. \& Reconstr. Surg 1960;25:117.

7. Cosnran B, Crikelair GF. The surgical treatment of keloids. Ju, M.C., Gaulin, J.C., And Lanes, R 1961;c27:335.

8. Fugimore R. Hiromato sponge fixation method for M. and ofugi, S: treatment of early scars. Plast \&reconstr. Surg, 1974;53:140.

9. Garb J, stone MJ. Keioids Review of the literature and a report of eighty cases. Am J.Surg 1942;58:315-335.

10. Griffith BH. Treatment of keloids With triamcinolone Triamonolone acelonice Plast. \& reconstr. Surg, 1966;38:202.

11. Harold M Trusler. Keloids and hypertrophic scars Thomas B. Bauer A.M.A. Arch surg 1948;57:539.

12. Heidingsfeld ML. keloids: Acomarative histologic Study, J.A.M A, 1909;53:1276.

13. Ketchum LG, Cohen, Hypertrophic scars and keloids, I K. and Masters, F.W. 1974; c53140.

14. Ketchum LD Smith. Treatment of hypertrophic scars, J. Robinson, D.W. and keloids and scar contracture by Triamcinolone acetonies' Plast. \& reconstr. Surg 1967;38:209.
15. Ketchum LG. Follow -up on treatment of Robinson, D.W., and liypertrophic scars and keloids Masters. F W withtriamcionlone $1971 ; \mathrm{c} 48: 256$.

16. Koonin AJ. The aetiology of keloids: a review of literature and new hypothesis. South African M.J 1964;3891:3-916.

17. Maguire HC. Treatment of keloids with Triamcinolone acetonide injected Intralesionally J.A.M.A 1965;192:325326.

18. Minkowitz F. Regression of massive keloid following Partial excision and post-operative intralesional administration of triamcionlone. Brit. Plast Surg 1967;20:432-435.

19. Murry RD. Kenalog and the treatment of hypertrophic Scars and keloids in Negroes and whites. Plast. \& Reconstr. Surg 1963;31:275-280.

20. Ramkrishnan KM, Thomas KP. Study of 1000 patients with keloids in south And Sundaramajan, C.R. India. Plast \& reconstr. Surg 1974;53:276.

21. Stark R. Plastic surgery. Harpes and Raw. New yark 1963.

22. Thomas PA. keloid of tire ear . Indian J. of plast. surg. 1971;40:20.

23. Tothurst DE. hypertrophic .scarring Breveted by Pressure A case report, Brit. J. plast .surg. 1965;30:218.

24. Vallis CP. Injection of keloids and hypertrophic scars With Dermo-Jet. Plast.\&reconstr. Surg 1973;52:434.

25. Ketchum Ld Cothen, K Master FW. Hypertrophic scars and keloids ;a collective Review plastreconstrsurg 1974;53:140154.

26. Peacock EE, madden JW. trier WC biologic basis of treatment of keloids and Hypertrophic scars south med. J 1970;63:755-707.

27. Ketchum LD. smith J.robinsondw, mesters FW. Treatment of Hypertrophic scars and keloids Andscars contracture by triamcinolone Acetonidec 1966;38:209-218.

28. Kiil J. Keloid treated with topical_injections of Triamcinolone acetonide (kenalog) immediate And long term result. Scared J. plastreconstr Sung 1977:11:169-172.

29. Griffith BH, Monroe CW. Mckinney P.A. fallow -up Study on the treatment of kilods with Triamcinolone acetonide plastreconstrsurg. 1970;46:145-150.

30. Babin RW. ceilleyRI combied modalities in the management of Hypertropic scars dud keloids J. otolaryngol 1979;8:457-460.

31. Darzi MA, Chowdi NA, Kaul SK, khan M. Evaluatoin Of various methods of treating keloids and hypertrophic Scars; a 10-years follow-up study of Br J. plast Surg 1992:45:374379.

32. Lawrence WT. in search of the optimal treatment Keloids: report of a series and a review of the literature Ann. plastsurg, 1951;27:164-178.

33. Alster TS, Nanni CA. Pulsed-dye laser treatment of Hypertrophic born scars. plastrecostr sung 1998;102:21902195.

34. Apfelberg DB, maser MR, White DN, Lash H. Failure of carbon dioxide laser excision of keloids. Lasers surg Med 1994;9;382-388.

35. Abergel RP, Merke CA, Lam TS, Dwyer RM, Lesavoy MA, Uitto J. Control of connective tissue meatabolism by lasers: recent developments and futire prospects. J Am Acad Dematol 1984;11:1142-1150.

36. Goldman MP, Fitzpatrick RE. Laser treamtnet of scers. Dermatolsurg 1995;21:685-687.

37. Alster TS. Laser treatment of scars. In Alster TS, Apefelberg DB, eds. Cosmetic Laser surgery. New York, NY: John Weight \&Sone 1996, 81-92. 